\title{
Centrichnus eccentricus revisited: A new view on anomiid bivalve bioerosion
}

Christian Neumann, Max Wisshak, Martin Aberhan, Peter Girod, Thomas Rösner, and Richard G. Bromley Acta Palaeontologica Polonica 60 (3), 2015: 539-549 doi:http://dx.doi.org/10.4202/app.00079.2014

Saddle oysters (Anomiidae) attach themselves to calcareous hard substrates by means of a calcified byssus that etches an attachment structure, referred to as ichnospecies Centrichnus eccentricus. Examination of rich material from the Late Cretaceous of central Europe extends the fossil record of this ichnotaxon and revealed a set of previously unrecognised morphological features which appear to be typical for this time period and the respective anomiid trace maker. Excellent preservation of a large number of trace fossil specimens with a complete set of morphological characters allowed a biometrical analysis and additional observations indicating a distinct substrate preference for belemnite rostra, a strong intra- and interspecific competition for settlement space, as well as interactions with durophaguous predators. Further implications for anomiid palaeobiology and palaeoecology arise from allometric shell growth and an etched outline suture in the substrate along the dorsal, lateral and ventral shell margins. These features enhanced a firm attachment and increased shear resistance, and thus are interpreted as an effective defence mechanism against shell-crushing enemies under the intensified predation pressure in marine environments in the Late Cretaceous.

Key words: Mollusca, Anomiidae, Centrichnus eccentricus, belemnite, trace fossil, attachment bioerosion, Cretaceous, Europe.

Christian Neumann [christian.neumann@mfn-berlin.de] and Martin Aberhan [martin.aberhan@mfn-berlin.de], Museum für Naturkunde, Leibniz Institute for Evolution and Biodiversity Science, 10115 Berlin, Germany; Max Wisshak [max.wisshak@ senckenberg.de], Senckenberg am Meer, Marine Research Department, 26382 Wilhelmshaven, Germany; Peter Girod [p.girod@gmx.de ], Holteistr. 2, D-10245 Berlin, Germany; Thomas Rösner, Elbestrasse 16, D-12045 Berlin, Germany; Richard G. Bromley [richard@bromley.dk], Rønnevej 97, 3720 Aakirkeby, Denmark. 
This is an open-access article distributed under the terms of the Creative Commons

Attribution License (for details please see creativecommons.org), which permits unrestricted use, distribution, and reproduction in any medium, provided the original author and source are credited.

FaF Full text $(1,304.7 \mathrm{kB})$ 